\title{
Quand la culture d'innovation fait écran à la culture technique
}

\section{When culture of innovation hides technical culture}

\author{
Marianne Chouteau ${ }^{1}$, Joëlle Forest ${ }^{1}$, Céline Nguyen $^{1}$ \\ 1 EA 4148 - S2HEP, Université de Lyon, marianne.chouteau@insa-lyon.fr, joelle.forest@insa-lyon.fr, \\ celine.nguyen@insa-lyon.fr
}

\begin{abstract}
RÉSUMÉ. Nous vivons dans une société artificielle et curieusement alors qu'on parle abondamment de culture littéraire, culture scientifique, culture numérique voire de culture artistique on ne peut que déplorer l'absence d'une culture technique. Ce constat n'est pas nouveau. Il fut largement débattu dans les années 1980 mais un constat s'impose malgré la richesse des propositions: la culture technique demeure la grande absente de notre quotidien et des discours politiques. Après avoir précisé ce que l'on entend par culture technique, la présente contribution s'interroge sur les raisons qui expliquent qu'une telle culture peine à se déployer. Ce faisant, elle souligne que la culture d'innovation fait écran à la culture technique.

ABSTRACT. Although we live in a digital and artificial society, a technical culture is not a subject of everyday life or of political debate. We usually hear about scientific culture and literary culture but rarely about technical culture and we deplore it. Why is it so difficult to acknowledge this culture ? This paper tries to find the reasons for those difficulties and argues that the culture of innovation actually hides the technical culture.

MOTS-CLÉS. Culture de l'innovation, culture technique, innovation.

KEYWORDS. Culture of innovation, technical culture, innovation.
\end{abstract}

\section{Introduction}

Au début des années 1980, Jocelyn De Noblet publiait un Manifeste pour le développement d'une culture technique soulignant que la technique "était condamnée à entrer par effraction » dans la culture (De Noblet, Culture technique et changement de société, 1981).

Cette effraction est vraisemblablement une référence à la pensée de Gilbert Simondon qui plaidait dès la fin des années 1950 pour la " possibilité d'une introduction de l'être technique dans la culture » (Simondon, Du mode d'existence des objets techniques, 2012).

« La culture est déséquilibrée parce qu'elle reconnaît certains objets, comme l'objet esthétique, et leur accorde droit de cité dans le monde des significations, tandis qu'elle refoule d'autres objets, et en particulier les objets techniques, dans le monde sans structure de ce qui ne possède pas de significations, mais seulement un usage, une fonction utile. » (Simondon, Du mode d'existence des objets techniques, 2012).

Cette absence de la technique du monde des significations pose de multiples problèmes :

Premièrement, on peine à voir combien nos objets techniques sont révélateurs de valeurs humaines et façonnent ainsi nos cultures. Si on occulte cela, il devient alors difficile de comprendre combien les objets techniques relèvent aussi de construction et de choix. Cela nous empêche également de voir à quel point ils sont porteurs de sens.

Deuxièmement, on enferme notre relation à la technique dans une relation d'aliénation émanant de l'objet technique alors que cette dernière réside selon Gilbert Simondon, non pas dans l'objet lui-même mais dans «cette méconnaissance de la machine, qui n'est pas une aliénation causée par la machine mais par la non connaissance de sa nature et de son essence [...] » (Simondon, Du mode d'existence des objets techniques, 2012). 
Ses propos sont relayés par Philippe Roqueplo dès 1983 lorsqu'il affirme que :

« la culture technique consiste dans la possession des connaissances et savoir-faire susceptibles de fonder un minimum de maitrise personnelle sur notre environnement et de contrôle sur l'activité de ceux dont la compétence s'avère indispensable. L'absence générale de cette culture constitue une cause d'aliénation généralisée. Son développement s'impose donc pour supprimer, autant que possible, cette aliénation »(Roqueplo, Penser la technique : pour une démocratie concrète, 1983).

Le spécialiste des usages Jacques Perriault [PER 98] va dans ce sens lorsqu'il met en évidence cette tendance qu'ont les intellectuels à considérer la technique sous le seul angle de l'asservissement. Enfin, l'initiateur du Manifeste cité plus haut affirme que c'est bien la culture technique qui permettrait à l'homme de maitriser son environnement [DEN 81] et non pas l'objet en tant que tel.

Force est malheureusement de constater que le panorama dressé il y 35 ans par Jocelyn De Noblet [DEN 81] demeure toujours d'actualité alors que les bouleversements actuels de la société nous invitent à réinvestir le concept de culture technique pour penser le sens des objets que nous concevons et à travers eux, le monde dans lequel nous vivons.

La question qui se pose est celle de comprendre pourquoi, alors que l'artificialisation de notre monde n'a jamais été aussi importante, la culture technique peine toujours à se déployer ? Comment et pourquoi sommes-nous passés d'une période où «la technique était l'objet de débats de société extrêmement fondamentaux (...) par la conception de l'homme qu'elle présuppose et le type d'humanité qu'elle construit » [HER 97] à une période où la technique n'est plus autant interrogée, ni pensée ? Roger Lesgards pose le même diagnostic :

«Les évolutions technologiques n'ont-elles pas entrepris de bouleverser notre notion du temps $[. .$.$] notre appréciation de l'espace proche autant que lointain, notre système de$ représentation du monde, notre rapport à la vie, à la pensée, au corps, à la maladie, au handicap, au travail, au loisir? Face à ces évolutions radicales, la réflexion est en retard, ou pire encore, en porte à faux » (Lesgards, L'empire des techniques, 1994).

Est-ce le concept de culture technique qui semble trop daté, dépassé ou trop idéologiquement connoté ?

L'hypothèse que nous formulons est que, dans une société où l'innovation est considérée comme vitale par $84 \%$ des dirigeants pour profiter de la reprise de l'économie mondiale [BCG 10], nous pensons davantage la production d'innovations plutôt que le sens que nous pourrions donner à la technique et notre rapport à elle. Dans ce contexte, l'avènement de ce que certains nomment la « culture d'innovation» relègue ainsi la culture technique au second plan.

Or, peut-on innover en l'absence d'une culture technique, si on ne voit pas que le monde a changé, que nous n'avons plus les mêmes modes de vie, aspirations, rêves, connaissances ? Ne sommes-nous pas condamnés à produire des innovations « incrémentales", voire dangereuses pour les humains et leur environnement en l'absence d'une culture technique ou, pour le dire autrement, si on laisse dans l'ombre la question du sens de l'innovation?

C'est précisément à ces questions que la présente contribution entend apporter des éléments de réponse. Pour ce faire, nous définirons dans un premier temps ce que recouvre le concept de culture technique. Nous étudierons ensuite les raisons de sa « relégation». Enfin, nous ferons un focus sur la culture d'innovation en montrant comment cette dernière fait écran à la culture technique l'empêchant ainsi de se développer. 


\section{Culture et culture technique}

\subsection{Une culture, des cultures?}

Définir le concept de culture technique implique de revenir quelques instants sur celui de culture. Nous ne prétendrons pas ici être exhaustives tant la tâche est ardue. Nous souhaitons simplement insister sur la dimension plurielle et ouverte de la culture et nous émanciper d'une vision consistant à établir une hiérarchie entre les cultures, entre ce qui est légitime et ne l'est pas. Dans cette perspective, la culture peut à la fois être définie au niveau individuel et au niveau collectif.

Au niveau individuel, la culture correspond à ce qui est assimilé et à ce qui imprègne l'esprit de chaque personne; cette culture peut être différente d'un individu à un autre ; et pour une même personne elle varie dans le temps ; elle s'enrichit par l'éducation, par l'expérience, par les réflexions personnelles, en un mot par « la vie ».

Au niveau collectif, la culture, dans son sens le plus étendu, peut être entendue comme la somme des idées, des sentiments, des habitudes, des valeurs, pratiques... qui ont cours pour un individu dans un groupe humain. Au sens anthropologique et ethnologique la culture peut en effet être définie comme

« l'ensemble des formes acquises de comportements qu'un groupe d'individus, unis par une tradition commune, transmettent à leurs enfants [...] Ce mot désigne donc, non seulement les traditions artistiques, scientifiques, religieuses et philosophiques d'une société, mais encore ses techniques propres, ses coutumes politiques et les mille usages qui caractérisent sa vie quotidienne : modes de préparation et de consommation des aliments, manière d'endormir les petits enfants, modes de désignation du président du Conseil, procédure de révision de la Constitution, etc. » (Mead, 1953 in Gimello-Mesplomb F., Enjeux et stratégies de la politique de soutien au cinéma français : un exemple : la nouvelle vague, 2000).

C'est, pour le dire autrement, ce qui permet aux individus de ce groupe de vivre et de «faire société ». C'est donc cette culture qui permet de définir un groupe, à un moment et dans un territoire donné, à travers ce qui fait sens pour lui.

Dès les années 1970, le courant des Cultural studies a plaidé pour l'existence de plusieurs cultures et pour que n'opèrent plus une hiérarchie entre des cultures légitimes et d'autres qui ne le seraient pas comme évoqués précédemment. Par exemple, dans le cas du numérique, on peut concevoir que la culture numérique juvénile est à ce titre :

« un ensemble de valeurs, de pratiques et de connaissances qui s'inscrivent dans l'immédiateté, où la communication (partout et tout le temps) et les nouveaux médias jouent un rôle prépondérant pour créer et maintenir une forme de sociabilité communautaire et permettre une construction identitaire » (Dauphin, Culture et pratiques numériques juvéniles : Quels usages pour quelles compétences ?, 2012).

L'utilisation du numérique (médias sociaux, jeux en ligne, etc.) fait sens pour les jeunes dans la mesure où elle correspond aux besoins et attentes de ce groupe social en proie à des questions de construction de soi et en quête d'indépendance. L'intérêt de cette approche culturelle (qui ne traite pas explicitement de la culture technique) réside dans le fait qu'elle accorde une grande importance à la relation et donc au sens, que les groupes, souvent constitués en "publics » possèdent avec les « objets » peuplant leur quotidien, notamment les objets culturels (séries TV, musique indépendante, films d'action, ...).

Yves Deforge met quant à lui en exergue la dimension réflexive propre à la culture : 
« La culture réside dans un état mixte, elle est le savoir plus une aptitude à structurer le savoir. Le savoir n'est pas fait que du présent, il englobe aussi le passé et même, pour une part, le futur. La culture est donc une aptitude à créer dans l'épaisseur du savoir, des lignes de force, des courants qui relient des faits et les prolongent au-delà du présent. En bref, est cultivé celui qui a le savoir et qui sait l'organiser en surface et en profondeur. » (Deforge, De l'éducation technologique à la culture technique, 1993).

Le terme de culture étant polysémique il n'est pas surprenant de constater que celui de culture technique a lui-même donné lieu à des définitions variées.

\subsection{Approches de la culture technique}

Plusieurs auteurs, militants ou non, ont effectivement depuis les années 1970 produit des définitions de la culture technique.

Tout d'abord, Philippe Roqueplo [ROQ 83], dans son ouvrage Penser la technique, définissait la culture technique à partir d'une approche multi-niveaux. Il repérait ainsi trois niveaux :

«1. Le niveau d'assertions factuelles du type "le monde est de plus en plus constitué d'objets techniques".

2. Celui où sont associées aux faits qui viennent d'être énoncés (niveau 1) des conséquences personnelles et sociales. Ces conséquences sont ici dénotées par le mot d'aliénation.

3. Le niveau des implications comportementales (éthiques ou politiques) résultant des conséquences précédentes : il va de soi qu'il faut lutter contre l'aliénation, et par conséquent promouvoir la culture technique, qui dans la réponse proposée, se définit précisément comme principe d'appropriation et de contrôle et de fait comme une désaliénation.

Il resterait d'ailleurs à élucider jusqu'à quel point ce n'est pas la conviction éthique et politique énoncée au niveau 3 qui fournit l'éclairage conduisant à l'évidence factuelle de départ (niveau 1), auquel cas l'analyse située au niveau 2 (la double aliénation) servirait de pivot à un complexe indissociable d'idées et de prescriptions intrinsèquement contenues dans la notion de culture technique.» (Roqueplo, Penser la technique: Pour une démocratie concrète, 1983).

Cette partition a ceci d'intéressant qu'elle définit clairement la culture technique à partir des différents rapports et engagements que l'on peut avoir aux objets qui nous entourent allant du simple constat que nous sommes dans un monde de plus en plus artificialisé à une approche plus humaniste permettant la réappropriation de notre environnement.

Yves Deforge propose une autre manière de définir la culture technique. Il plaide tout d'abord pour une «réflexion sur la technologie [qui] donne une culture technique en relation avec le monde environnant » [DEF 96]. Il poursuit : la culture technique :

« exige la connaissance objective et opératoire du monde technique (et scientifique) mais aussi, au-delà, une aptitude à la pensée symbolique et universelle, c'est-à-dire proprement philosophique » (Deforge, Technique et culture, 1996).

La culture technique ainsi conçue se veut une pensée systémique de la technique, dans le sillage de la conception des physiocrates, proche de l'idée de technologie réflexive (ou encore mécanologie) de Lafitte [DEF 93].

L'auteur va plus loin car il conçoit une culture technique pour l'action ou agissante: « ce que nous suggérons, c'est de mettre la technique et la science sous le contrôle d'une culture clairvoyante et agissante » [DEF 96]. En ce sens, la culture technique constitue des savoirs opérants, en situation, avec 
l'intention de produire de la technique « en conscience » si l'on peut dire. Il ne s'agit pas de développer une technique aveugle ni aveuglément mais pensée en accord avec la société. Il plaide pour une culture technique agissante pour tous

«participant à la préparation de tous à la maitrise sociale de la technique, non en vue d'une opposition systématique et ayant souvent peu d'effet mais en vue d'inculquer les principes généraux d'action - une nouvelle éthique - valable pour tous » (Deforge, De l'éducation technologique à la culture technique, 1993).

Cette culture au fond très accessible ne serait pas figée dans le sens où elle serait constituée de savoirs mais aussi de l'aptitude « à structurer le savoir » [DEF 93] pour agir dans le monde dans lequel nous sommes.

\section{La culture technique telle que nous l'entendons}

Les définitions qui précèdent ont mis en avant la possibilité de penser cette culture technique à partir d'une approche multi-niveaux, mais aussi de la penser dans sa dimension réflexive et agissante. Pour notre part ces points de vue ne sont pas contradictoires et doivent être rassemblés. Il nous parait par ailleurs important d'intégrer un volet « acteur» dans la définition de la culture technique et ce, dans la perspective que propose Yves Deforge. Précisons notre point de vue.

La culture technique peut en effet être pensée à partir d'une approche multi niveaux :

- à un premier niveau il s'agit de connaissances relatives à la structure de l'objet, aux relations entre les différents modules qui le composent etc. Précisément, l'approche fonctionnelle permet de décrire sous forme schématique (décomposition structurée de la finalité en fonction de service, de la fonction en fonction technique) le fonctionnement de l'objet technique, d'associer à chaque bloc fonctionnel les composants réalisant une fonction et d'établir un croquis du circuit d'alimentation énergétique et circuit informationnel. Ces connaissances permettent de comprendre de quoi est fait un objet technique et comment il fonctionne ce qui a conduit Bruno Jacomy à dire que ce premier niveau rassemble l'ouvrier, le technicien et l'ingénieur.[JAC 93]

- à un second niveau il s'agit de connaissances et savoir-faire développés et mobilisés pour user des objets techniques qui nous entourent. A un premier niveau ce peut être un mode d'emploi qui permet à l'usager d'un objet technique de le faire fonctionner. Si comprendre comment on utilise un objet technique, ou pour le dire autrement, ce que les objets techniques font aux usagers (volet de l'usabilité dans le sillage des travaux de Madeleine Akrich), conduit à considérer les compétences mobilisées dans l'action, soulignons cependant que les travaux centrés sur l'usage ont permis de considérer également «ce que font les usagers aux objets techniques » et de reconnaître ainsi l'activité de ces derniers dans les «trajectoires » [PER 98] des objets techniques. Cet intérêt pour l'usager a ainsi permis de prendre la mesure des connaissances, logiques [PER 98], et savoir-faire développés pour s'approprier les objets et créer de nouveaux usages. Les travaux de Michel de Certeau [DEC 90] autour du braconnage sont à ce propos fondateurs. L'histoire de la conception du Minitel en France dès la fin des années 1970 est elle aussi très intéressante : elle montre à la fois comment les instances publiques ont souhaité la participation des futurs utilisateurs (choix du clavier, phases de test) lors de la conception, mais aussi comment les utilisateurs ont finalement plébiscité certains usages dont la portée n'avait pas été mesurée (la messagerie conviviale a en effet connu un succès fulgurant non prévu) [SCH 12].

- le dernier niveau est constitué d'un ensemble de savoirs sur les modes d'existence des objets techniques qui permettent de penser et concevoir les objets techniques et le sens dont ils sont porteurs. C'est à ce niveau qu'il est possible de considérer que les techniques s'inscrivent et modifient des relations de pouvoir, le sentiment d'appartenance [BON 13], et qu'en ce sens, elles ne sont pas en 
dehors des sociétés qu'elles façonnent et qui les voient se développer. C'est par exemple s'intéresser aux évolutions récentes de nature politique et sociologique autour du « Sacre de l'amateur » [FLI 10], à une certaine forme d'empowerement rendu possible par Internet et les innovations liées au numérique.

A ces trois niveaux on peut associer des " points de vue » : au premier niveau celui du technicien, au second celui de l'usager et au dernier celui du citoyen, que peut prendre un même acteur. Par exemple l'ingénieur lorsqu'il « emprunte » le rôle du technicien sera essentiellement préoccupé par les qualités fonctionnelles du produit qu'il étudie ou conçoit. Lorsqu'il emprunte les habits de l'usager, il mobilisera les valeurs, normes et habitudes de la personne qui utilisera l'objet ou service sur lequel il travaille. Il replacera l'utilisation de l'objet en contexte en tenant compte de «l'épaisseur sociale » que l'usage revêt. Il considérera qu'il peut exister plusieurs types d'usages voire d'usagers pour un même objet (jusqu'au non-usage) ou encore que l'usage évolue dans le temps ou d'une aire géographique à une autre. Lorsqu'il se positionne enfin comme citoyen alors son regard est plus global, sans doute plus éthique afin de s'interroger sur les limites à poser au déploiement d'un objet technique mais aussi sur le sens donné à celui-ci et son déploiement. Le citoyen s'interroge, se projette sur ce que la technique fait à l'organisation du monde, à la distribution des pouvoirs, les modes de participation et de décision.

Quel que soit le niveau considéré la culture technique à une portée agissante. Au premier niveau c'est elle qui permet de garantir la robustesse de la solution développée, au niveau de l'usager c'est elle qui lui permet d'user de l'objet mais aussi de le façonner selon ses envies, au dernier niveau c'est elle qui lui permet de prendre des décisions « politiques ».

La culture technique, telle que nous l'entendons, est non seulement un moyen de sortir les individus de leur aliénation et de leur statut de simples consommateurs de dispositifs techniques, elle est aussi indispensable si nous voulons chacun, en tant que citoyen, être à même de participer à la réflexion sur les grands défis qui se posent et impliquent de prendre des décisions qui concernent non seulement notre avenir mais aussi celui des générations à venir. Comme le souligne Roger Lesgards dans l'avantpropos de L'Empire des techniques :

«Les évolutions technologiques n'ont-elles pas entrepris de bouleverser notre notion du temps $[\ldots]$ notre appréciation de l'espace proche autant que lointain, notre système de représentation du monde, notre rapport à la vie, à la pensée, au corps, à la maladie, au handicap, au travail, au loisir? »(Lesgards, L'empire des techniques, 1994).

C'est nous semble-t-il à ce dernier niveau que peuvent être pensées les solutions de rupture que requièrent les grands défis contemporains, défis empreints d'un humanisme moderne centré sur l'amélioration des conditions de vie de l'homme (vieillissement de la population, respect de la vie privée, droits à la déconnexion, disparition et à l'oubli), notre rapport à la nature (prise en compte des préceptes du développement durable) et non comme le seul résultat d'une injonction impensée, d'une course à la célébrité, d'une consommation effrénée voire d'une mode. Et c'est précisément parce que la culture technique, contrairement à la culture d'innovation comme nous allons le voir dans ce qui suit, considère la question du sens qu'elle est, selon nous, à même de produire les innovations radicales induites par les défis d'aujourd'hui. Penser le sens des objets et à travers eux celui de notre humanité revient en effet à mettre en évidence la dimension réflexive de la culture technique, dimension qui permet de s'émanciper de la rhétorique de l'innovation [DEL14] héritière du dogme de la notion de progrès et d'une conception de l'évolution en terme d'une inévitable destruction créatrice [CHA 14]. L'innovation doit ainsi pour le dire autrement être arrimée à une finalité un projet politique.

\section{Pourquoi la culture technique peine-t-elle encore à se développer?}

Dans ce contexte, nous avons identifié trois raisons qui pourraient expliquer le manque de reconnaissance de la culture technique. 
La première tient au statut même de la technique. Nous avons déjà eu l'occasion de souligner combien l'avènement d'une Techno-logie avait été tardif, la technique n'étant pas considérée comme objet de connaissance [FOR 12]. On peut d'ailleurs supposer que la définition qui a pu être donnée de la technologie, et qui a laissé dans l'ombre la question du sens, a conduit à un sentiment de méfiance vis-à-vis d'une «technique » alors pensée comme englobante, c'est-à-dire se déployant de façon identique malgré la diversité des cultures. Elle a pu même être considérée comme totalitaire car accusée, par l'apport d'une solution unique, de détruire la culture initiale d'une communauté, d'une aire géographique, etc., On peut aussi faire l'hypothèse que la technologie, pensée comme un ensemble de connaissances visant à organiser le travail et la production a conduit à associer la technique à une approche utilitariste, aliénante et non réflexive.

La deuxième explication, étroitement liée à la précédente, tient au statut même de la Culture avec un grand « $\mathrm{C} »$. Celle-ci contient un ensemble de connaissances jugées légitimes, liées à des pratiques culturelles telles que le théâtre, la littérature, la visite de musées d'art ... Or, comme le soulignait Maurice Magnien, il faut « braver les péchés latins qui font qu'au-delà de la littérature il n'y a pas de culture » [DEN 94]. On retrouve le constat dressé quelques années plus tôt par Jocelyn De Noblet :

«Contradictions sans doute plus graves, beaucoup d'enseignants, d'écrivains ou de diffuseurs d'information en sont restés aux stéréotypes de la culture légitime : la technique, l'entreprise, le travail sont loin de leurs valeurs et de leurs préoccupations, comme les nouveaux outils technologiques restent hors de leur pratique professionnelle, comme le statut de l'enseignement technique reste mineur, et aux yeux de beaucoup, infra-culturel ». (De Noblet, Culture technique et changement de société, 1981).

Il sera repris par Jack Lang, alors ministre de la Culture et fer de lance de la démocratie culturelle à l'occasion de l'ouverture d'un colloque consacré en 1983 au design et à la création industrielle :

«Et très curieusement, cette distinction entre le monde réel et le monde de la réflexion recouvre une autre distinction, qui n'est pas moins perverse, et qui n'est pas sans rapport avec la première : distinction entre les arts nobles, ceux que les rhétoriciens du XIX ${ }^{\mathrm{e}}$ siècle ont érigés en forme d'arts dignes des humanités, des universités, de la réflexion et du monde civilisé et de l'autre côté, les arts roturiers, ou les arts mineurs, ceux qui se trouvent le plus souvent liés au monde de l'industrie. Arts nobles, la musique symphonique, la haute littérature, la philosophie, la rhétorique, l'histoire, les sciences de l'homme, tout ce qui permet de contempler, d'observer le monde. Mais dès qu'on se rapproche de la vie réelle, dès qu'il s'agit de se salir un peu les mains, alors il y a une certaine répugnance à considérer que l'action d'inventer peut être érigée au niveau d'une activité noble et majeure. » (Lang, 1983 in Gimello-Mesplomb, Enjeux et stratégies de la politique de soutien au cinéma français : un exemple : la nouvelle vague, 2000).

Jacques Perriault ira quelques années plus tard jusqu'à parler du mépris très français pour le travail et l'industrie : «que de mépris ou d'ignorance chez les intellectuels pour l'artisanat, l'enseignement technique, l'enseignement professionnel [PER 98], mépris qui remonte, selon Théodore Zelding, au fossé établi entre la culture générale et humaine et les milieux scientifiques, techniques et industriels [DEN 94]. Si nous ne remettons pas en cause l'importance de cette Culture, ni ne hiérarchisons les différentes formes de savoirs, il nous semble primordial d'affirmer que les objets et savoir-faire techniques entrent bien, eux aussi, en tant qu'œuvres, dans le monde des significations.

La troisième explication tient à une conception restrictive du concept de culture technique. Conception que l'on rencontre de façon générale dans les formations techniques de l'enseignement secondaire et plus particulièrement dans les écoles d'ingénieurs, lieu de formation des producteurs de technique. Dans ces dernières en effet, la culture technique ne se définit pas par sa capacité à nous « renseigner » sur nos sociétés et à les comprendre. Elle se définit d'abord comme un ensemble de 
connaissances de tous les éléments d'un objet ou système technique et de leurs relations fonctionnelles. La culture technique ainsi conçue, centrée sur la fonction et le but, apporte une satisfaction, un alibi, à une "pensée paresseuse » [BAC 38] car elle n'implique pas de s'interroger sur le sens et le rapport dudit objet à la société dans lequel il s'inscrit. L'ingénieur, pour le dire autrement, ne serait pas concerné par ce que cet objet «fait» à la société ou ce qu'il en dit mais juste par la robustesse fonctionnelle de l'objet qu'il conçoit.

\section{Une culture d'innovation qui fait écran}

Si les trois raisons évoquées précédemment jouent un rôle certain dans le fait que la culture technique n'a toujours pas la place qu'elle mérite, nous faisons l'hypothèse que c'est depuis quelques années l'avènement de ce que certains nomment «la culture de l'innovation » [ATT 11] qui lui fait écran et agit comme le principal frein à la diffusion de la culture technique.

Pensée comme le moteur des sociétés occidentales, l'innovation jouit en effet d'un véritable culte. $\mathrm{Ce}$ dernier s'inscrit en premier lieu dans des discours politiques, économiques et médiatiques aujourd'hui très prégnants. Xavier de la Porte, journaliste et essayiste français parle même d'une injonction à innover: "Dans l'injonction à innover, il y a l'idée que ce qui nous sortira de la crise, c'est aller de l'avant, c'est aller vers la nouveauté, c'est produire» [DEL 14]. Ainsi conçue, l'innovation n'est pensée qu'en terme de solution et non pas à partir des rapports que nous entretenons avec les objets techniques. L'innovation apparait en effet tantôt comme un moyen de répondre à des injonctions (nouvelles normes et réglementations), tantôt comme un moyen de faire face à la crise ou concurrence (notamment des pays à faibles coûts salariaux) voire même comme le vecteur permettant de distribuer des dividendes.

Soulignons cependant que si l'innovation possède un sens politique et stratégique évident pour l'entreprise elle laisse dans l'ombre la question du sens. On assiste en effet à un glissement d'une réflexion sur le sens de l'objet à une réflexion sur le sens de l'innovation pour l'entreprise ce qui est sensiblement différent. On rejoint par là même les propos de Thierry Ménissier lorsqu'il indique que "l'innovation ne noue pas, comme on le faisait dans la thématique du progrès, les inventions technologiques et la rationalisation de l'organisation à un dessein social et moral. » [MEN 11]. C'est dans le même esprit que s'entendent les propos du philosophe Eric Sadin lorsqu'il reproche au Président de la République, dans un dialogue à propos de son ouvrage « La vie algorithmique » [KYR 16], de « faire des courbettes » devant le PDG de Withings entreprise à la pointe des objets connectés. L'auteur critique en creux que l'impératif économique prenne le pas sur le sens de ces objets connectés. Il estime par exemple que l'usage des bracelets ou balances connectés ainsi que des Big Data engendre des comportements qui méritent d'être analysés pour ce qu'ils disent de notre rapport au corps (mesure permanente...), ou à notre libre-arbitre.

Par ailleurs, depuis plusieurs années, les études annuelles du cabinet de conseils en stratégie Booz \& co Global Innovation 1000 qui analyse les dépenses de R\&D des 1000 premières entreprises mondiales, soulignent que l'excellence de la recherche n'est pas le seul facteur impactant la performance en matière d'innovation. Ainsi, les études de 2011 et 2012 montrent la faible corrélation entre le niveau d'investissement en $R \& D$ et la performance des entreprises en termes de chiffre d'affaires ou de capitalisation. L'étude de 2011, menée auprès de 600 entreprises leaders en matière d'innovation dans le monde, de tailles différentes et appartenant à des secteurs industriels variés, révèle en outre que $47 \%$ d'entre elles considèrent la culture d'innovation comme un facteur clé.

Le problème qui se pose est que la corrélation faite entre «capacité d'innovation » et «culture d'innovation» s'est traduite par une abondante littérature recensant un ensemble de préconisations exprimées sous la forme de : « 7 conseils pour développer une culture d'innovation en entreprise » [LET 11] ou " 25 mesures ou moyens pour développer une culture d'innovation » [FOR 14], destinées à faire émerger cette culture d'innovation. Or, lorsqu'on se penche attentivement sur ces 
préconisations on s'aperçoit rapidement que la culture d'innovation est réduite à un ensemble de recettes organisationnelles : «Donner l'autonomie nécessaire et une liberté d'action aux employés », « impliquer les employés dans les processus d'innovation », « Accorder le droit à l'erreur et susciter la prise de risques $\rangle^{1}$ etc. Cet ensemble de mesures est comparable à ce que l'on peut lire dans la fiche intitulée «Instaurer une culture et un goût de l'innovation » issue des Techniques de l'ingénieur, sorte de « bible » des ingénieurs, qui vise à « changer l'état d'esprit et déployer une gamme de dispositifs à tous les niveaux hiérarchiques de l'entreprise » [ATT 11].

La situation est sensiblement la même au niveau des politiques publiques de l'innovation. En effet, la mise en place du Système Français de Recherche et d'Innovation (SFRI) a coïncidé avec le développement économique de la France dans l'après-guerre. Si son organisation correspondait bien à une dynamique de « rattrapage technologique » durant la période des Trente Glorieuses, elle a très vite montré ses limites lorsqu'il s'est agi pour la France d'innover par elle-même et de faire face aux grands défis sociétaux contemporains dans les domaines-clé comme la santé, l'agriculture, les transports, l'énergie. C'est dans le sillage de cette prise de conscience qu'est née la politique des pôles de compétitivité en 2004 ainsi que la stratégie nationale de recherche et d'innovation en 2009. Plus près de nous, dès 2012, le Gouvernement a engagé une politique pour l'innovation dans le cadre du « Pacte pour la compétitivité, la croissance et l'emploi qui se veut une politique globale de transformation de la société pour construire le nouveau modèle français. C'est dans ce contexte qu'a émergé le plan «Une nouvelle donne pour l'innovation » qui se fixe une ambition globale : celle de faire de la France une terre d'innovation et fonde cette «nouvelle donne » sur 40 mesures transverses regroupées sous 4 axes. Dans le cadre de ce plan, la culture d'innovation apparait un facteur clé de l'innovation comme on le constate dans le nom même de l'axe 2 : développement de la culture de l'entrepreneuriat et de l'innovation. Cette relation semble d'ailleurs correspondre à une vision largement partagée puisque selon le rapport Coping with the crisis, the European way [ERN 14] le développement d'une culture d'innovation apparait être le second facteur clé à mettre en œuvre en Europe.

Leader in innovation
what are the main areas of reform to make European a leader in innovation?

\begin{tabular}{ll|l}
\hline Improve education and training in new technologies & $\mathbf{4 6 \%}$ & \\
\hline Develop a culture of innovation and creativity & $36 \%$ & \\
\hline Increase tax incentives for innovative companies & $32 \%$ & \\
\hline Develop entrepreneurship & $\mathbf{2 6 \%}$ & \\
\hline Develop joint research programs at the European level & $\mathbf{2 5} \%$ & \\
\hline Develop venture capital and other financial tools & $\mathbf{2 1} \%$ & \\
\hline
\end{tabular}

Source: Ernst \& Young's European attractiveness survey 2013 (total respondents: 808).

Tableau 1. Quels facteurs-clés pour le développement de l'innovation en Europe (Ernst \& Young, 2013)

L'idée de culture technique (quoi qu'elle reste ici associée à la culture scientifique sans doute par habitude) n'apparait que dans l'action 3 dudit axe 2 : «Renforcer les interactions entre classes du secondaire et laboratoires de la recherche publique pour le développement de la culture scientifique et technique ».

On l'aura compris, ici encore l'accent est mis sur le développement d'une culture de l'innovation et non sur celui d'une culture technique. Cela ne serait pas grave si très rapidement l'idée de culture d'innovation n'était pas très rapidement réduite, comme on l'a vu précédemment, à un ensemble de recettes organisationnelles qui évacuent la question du sens de ce que l'on conçoit.

\footnotetext{
${ }^{1}$ Ensemble de recettes disponibles sur : https://creativite33.com/2014/01/31/moyens-culture-innovation/ [consulté le 16 mai 2016]
} 


\section{Conclusion}

Dans la présente contribution nous avons proposé d'actualiser le concept de culture technique au regard des enjeux actuels et ce notamment, grâce aux auteurs qui ont œuvré pour son développement il y a 20 ans et plus. Notre définition consiste à penser la culture technique selon trois niveaux (des fonctions, de l'utilisation et de la signification) et à plaider pour que ces niveaux soient associés à des points de vue qu'il convient de penser ensemble : points de vue du technicien, de l'usager et du citoyen. Nous nous sommes alors attachées à comprendre pourquoi cette culture technique peine à se déployer. Nous avons indiqué que la principale raison tient au fait que la culture d'innovation, qui est principalement considérée sur le registre de recettes organisationnelles et de l'injonction, laisse dans l'ombre la question du sens attribué à la technique et, par là même fait écran à l'avènement de la culture technique telle que nous avons pu la définir.

Nous sommes intimement persuadées que l'évolution de notre société et son artificialisation constante exigent que la culture technique revienne au premier plan et qu'elle acquiert ce statut réflexif et agissant pour que chacun d'entre nous comprennele sens et les significations de la technique. De même, il nous paraît central de réaffirmer que l'innovation radicale ne requiert pas seulement une culture d'innovation de nature organisationnelle mais bel et bien une culture technique à même de nous donner la possibilité de concevoir et de proposer des objets techniques pensés dans et pour la société.

Développer et diffuser la culture technique prend également tout son sens dans la formation des ingénieurs qui seront au cœur de la conception et la production technique. On le voit, depuis quelques années la formation à l'innovation est montée crescendo dans les écoles d'ingénieurs. Elle touche tant les enseignements purement techniques mais également ceux de sciences humaines et sociales. Pourtant, force est de constater que, si l'innovation, semble aujourd'hui admise comme une composante à part entière de la formation de tout élève ingénieur, il manque un consensus sur ce que l'on entend effectivement par formation à l'innovation. Trop souvent encore, ladite formation reste réduite à une approche fonctionnelle ou instrumentale parfois proche du culte de l'innovation. Nous faisons néanmoins le pari que, l'artificialisation du monde aidant, la culture technique deviendra un passage obligé où la technique un élément de pensée ?

\section{Bibliographie}

[ATT 11] ATTIAS D., « Instaurer une culture et un goût de l'innovation », Techniques de l'ingénieur, 2011.

[BAC 38] BACHELARD G., Formation de l'esprit scientifique, Vrin, Paris, 1938.

[BCG 10] BCG., « Innovation 2010 », https:/www.bcg.com/documents/file42620.pdf, 2010.

[BON 13] BonneuIl C., Joly P-B., Sciences, techniques et société, Collection Repères, La Découverte, Paris, 2013.

[BOO 11] Booz \& Compagny, "Why Culture Is Key: The 2011 Global Innovation 1000", http:/www.strategyand.pwc.com/media/file/Strategyand-Global-Innovation-1000-2011-Webinar.pdf, 2011.

[CHA 14] CHABOT P., « Progress, innovation, transition », https://gaite-lyrique.net/rencontre/progres-innovationtransition, 2014.

[DAU 12] DAUPHIN F., «Culture et pratiques numériques juvéniles: Quels usages pour quelles compétences ? », Questions vives, ${ }^{\circ} 17$, https://www.bcg.com/documents/file42620.pdf, 2012.

[DEC 90] De CERTEAU M., L’invention du quotidien. T.1 Arts de faire, Gallimard, Paris, 1990.

[DEL 14] DE LA PORTE X., « Ce qui se cache derrière l'innovation », http://www.franceculture.fr/emissions/ce-qui-nousarrive-sur-la-toile/ce-qui-se-cache-derriere-linnovation\#, 2014.

[DEF 93] DEFORGE Y., De l'éducation technologique à la culture technique, Collections pédagogies, ESF Editeur, Paris, 1993.

[DEF 96] DEFORGE Y., «Technique et culture», Le nouvel éducateur, https://www.icem-pedagogiefreinet.org/node/14116, janvier 1996. 
[DEN 94] DENIEUIL P-N., «Technologie et société, la pensée d'un système : 15 années de Culture technique », Culture Technique,

http://documents.irevues.inist.fr/bitstream/handle/2042/32893/C\%26T_1994_30_4.pdf.txt?sequence=2, 1994.

[DEN 81] DE NOBLET J., « Culture technique et changement de société », Culture technique, n6, p. 11-47, 1981.

[ERN 13] ERNST \& YOUNG, "Coping with the crisis, the European way", http:/www.ey.com/Publication/vwLUAssets/European-Attractiveness-Survey-2013/\$FILE/European-AttractivenessSurvey-2013.pdf, 2013.

[FLI 10] FLICHY P., Le sacre de l'amateur. Sociologie des passions ordinaires à l'ère du numérique, La république des idées, Paris, 2010.

[FOR 12] FOREST J., FAUCHEUX M., (dir.), New Elements of Technology, UTBM Editions, Belfort, 2012.

[FOR 14] FORTIN A., «25 moyens pour développer une culture d'innovation », https://creativite33.com/2014/01/31/moyens-culture-innovation/, 2014.

[GIM 00] Gimello-MesplomB F., Enjeux et stratégies de la politique de soutien au cinéma français : un exemple : la nouvelle vague, thèse de second cycle, université Toulouse 2, 2000.

[HER 97] HERIARD-DUBREUIL B., Imaginaire technique et éthique sociale - Essai sur le métier d'ingénieur, De Boeck Université, Bruxelles, 1997.

[JAC 93] JACOMY B., « Culture technique de l'ingénieur », Technique de l’ingénieur, ref T40, 1993.

[KYR 16] KYRIOU A, SADIN E., L'âge de la mesure de la vie, http://www.culturemobile.net/visions/eric-sadin-agemesure-vie, 2016.

[LES 94] LeSGARDS R., « Avant-propos », in BAYle ET AL., L'empire des techniques, p. 7-11, Le Seuil, Paris, 1994.

[LET 11] LE TAREAU A., «Sept conseils pour développer une culture d'innovation en entreprise ", $\mathrm{http} / /$ www.generationinc.com/management/creativite-et-innovation-management/7-conseils-pour-developper-uneculture-d-innovation-en-entreprise, 2011.

[MEN 11] MENISSIER T., « Philosophie et innovation, ou philosophie de l'innovation ? » Klesis - Revue philosophique, $\mathrm{N}^{\circ} 18$, Varia, 2011

[PER 98] Perriault J., La logique de l'usage, L'Harmattan, Paris, 1998.

[ROQ 83] RoQuePlo P., Penser la technique. Pour une démocratie concrète, Le Seuil, Paris, 1983.

[SCH 12] SCHAFER V., THIERRY B., Le Minitel. L'enfance numérique de la France, Nuvis, Cigref, Paris, 2012.

[SIM 12] Simondon G., Du mode d'existence des objets techniques, Aubier, Paris, 2012. 